J. Clin. Chem. Clin. Biochem.

Vol. 19,1981 , pp. $169-171$

\title{
Eine verbesserte Methode zur selektiven Albuminbestimmung mit Bromkresolgrün auf dem SMA $^{\mathrm{R}} 12 / 60$
}

\author{
Von F. Keller, K. Feldmann und F.-J. Metz \\ Medizinische Universitätsklinik (Direktor: Professor Dr. H. A. Kühn) Würzburg
}

(Eingegangen am 19. Mai/4. Oktober 1980)

\begin{abstract}
Zusammenfassung: Bestimmungen von Albumin im Serum auf dem SMA ${ }^{\mathrm{R}}$ 12/60 mit Bromkresolgrün zeigen im Normalbereich verglichen mit elektrophoretisch bestimmten Werten eine gute Ubereinstimmung. Im klinisch relevanten Bereich der Hypalbuminämie werden dagegen große Abweichungen festgestellt. Eine Verkürzung der Reaktionszeit zwischen Bromkresolgrün und Serum erbringt eine bessere Übereinstimmung der Albuminwerte beider Methoden im gesamten Meßbereich.
\end{abstract}

An improved method for selective determination of serum albumin by the bromcresol green method, using the $S M A^{\mathrm{R}} 12 / 60$

Summary: The estimations of serum albumin obtained with $\mathrm{SMA}^{\mathrm{R}} 12 / 60$ by the bromcresol green method are in good agreement with values determined by electrophoresis only.in the normal range. Interestingly marked discrepancies occur in the clinically relevant cases of hypalbuminosis. The shortening of the reaction time between bromcresol green and serum results in a better agreement between the values obtained with SMA $^{R} 12 / 60$ and the values determined by electrophoresis over the whole range.

Die von Rodky vorgeschlagene Methode zur Bestimmung von Serumalbumin mit Bromkresolgrün (1) wurde von Doumas (2) auf Analysenautomaten adaptiert. Die Summe der Erfahrung aus zahlreichen Verbesserungsvorschlägen ist in die derzeit gültige Arbeitsvorschrift der $\mathrm{Fa}$. Technicon (3) eingegangen, wobei eine gewisse Optimierung erreicht wurde. Bei Serumalbuminbestimmungen nach dieser Arbeitsvorschrift im Routinebetrieb fiel auf, daß zwar im Normalbereich eine gute Übereinstimmung zwischen den Werten aus der Serumelektrophorese und den am SMA ${ }^{R} 12 / 60^{1}$ ) bestimmten Werten zu erzielen war, jedoch gerade im klinisch relevanten Bereich der Hypalbuminämie große Differenzen zu beobachten waren $(4,5)$.

\section{Material und Mèthoden \\ Sera}

Von 45 unselektierten Seren aus der Routine wurden an einem Tag nach der Originalmethode Albuminbestimmungen mit Bromkresolgrün durchgefuhrt. Gleichzeitig wururden die Werte durch elektrophoretische Bestimmungen kontrolliert und in der modifizierten Anordnung am. SMA 12/60 der Albuminwert nochmals bestimmt.

\footnotetext{
1) SMA 12/60: geschütztes Warenzeichen der Fa. Technicon GmbH, Bad Vilbel.
}

\section{Bromkresolgrün-Methode am SMA $12 / 60$}

Bei der Originalmethode (3) zur Bestimmung des Serumalalbumins auf dem SMA 12/60 wird das Bromkresolgrün-Reagenz ( $\mathrm{pH} 4,2$ ) mit der verdünnten Serumprobe gemischt und mit einer zeitlichen Verzögerung von etwa 5 Minuten der Adsorptionsmessung zugeführt.

Modifizierte Bromkresolgnïn-Methode am SMA 12/60

In der modifizierten Anordnung wird die Reaktionszeit zwischen Albumin und Bromkresolgrün auf etwa 15 Sekunden reduziert. Um die notwendige Verkürzung der Reaktionsdauer zu erreichen, wurden die Glaswendeln des Cartridge's einschließlich der Phasing-Coil aus der Reaktionsstufe in die Verdünnungsstufe verlegt. Der Zustrom der vorverdünnten Serumprobe zum Bromkresolgrün-Reagenz erfolgt oberhalb der Montageplatte. Um eine optimale Durchmischung der beiden Reaktanden zu gewährleisten, wird eine Glaskapillarwendel mit einem Innendurchmesser von $0,75 \mathrm{~mm}$ und einer Gesamtlänge von $50 \mathrm{~cm}$ auf 8 Windungen verwendet. Der Zufluß dieser Wendel wurde direkt am Fitting angesetzt und das Ende möglichst knapp über ein kurzes Schlauchstück (116-0536-12) mit der Küvette verbunden. Das vollständige Flußdiagramm ist in Abbildung 1 schematisch skizziert. Die Flußßraten blieben im Vergleich zu den Angaben der Originalmethode unverändert (3). Zur Messung nach der modifizierten Methode wurden die Originalreagenzien von Technicon (T 010573) benutzt, alle Mengen und Konzentrationen wurden beibehalten, mit Ausnahme der Konzentration für Brij 35, die von $1 \mathrm{~g} / \mathrm{l}$ auf $1,5 \mathrm{~g} / \mathrm{l}$ erhöht wurde. Die Kalibrierung erfolgt mit SMA-Referenzserum T (Lot B 9 H 745), während die Präzision mit Kontrollogen LP (Lot B 3203 C) von den Behringwerken kontrolliert wurde. 


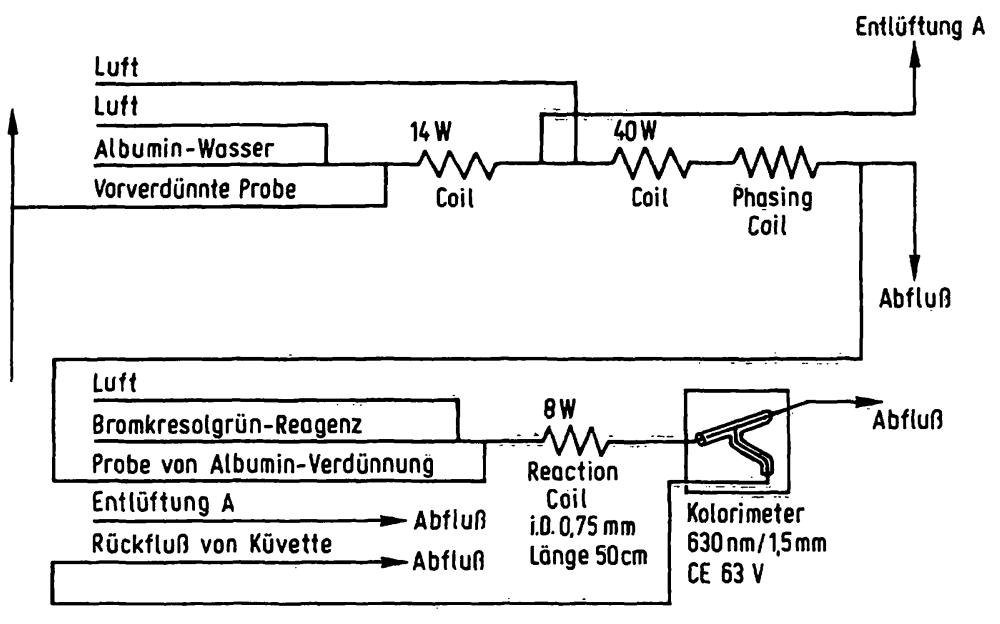

Abb. 1. Flußdiagramm zur Bestimmung des Serumalbumins mit Bromkresolgrün als Farbreagenz auf dem SMA $12 / 60$ nach der modifizierten Methode.

\section{Elektrophorese}

Auf Cellulose-Acetat-Folie der Fa. Sartorius (Nr. 12200 HB) wurden die Serumproben von einer Dispocard (Fa. Pratiga) mit einem modifizierten Stempel der Fa. Bender und Hobein aufgetragen. In diesem Stempel waren die Drahtbügel der Einzelelemente durch das Auftragsystem der Fa. Saitron ersetzt worden und zur simultanen Abnahme von acht Proben der Geometrie der Dispocard angepaßt. In einer Kammer der Fa. Saitron (5001) wurden die Seren in einem Diethylbarbiturat-Puffer (pH 8,6) 25 Minuten bei einer konstanten Spannung von $250 \mathrm{~V}$ elektrophoretisch aufgetrennt. Färben (Ponceau S), Fixieren und Klären erfolgte mit den Reagenzien der Fa. Bender und Hobein. Die densitometrische Auswertung wurde an einem Saitron-Densitometer (807) durchgeführt. Als Kontrollserum für die Elektrophorese wurde Kontrollogen L (Lot. Nr. 3112) verwendet. Zur Berechnung der Absolutwerte der Serumfraktionen wurde das Gesamteiweiß nach der Biuret-Methode am SMA 12/60 eingesetzt (T 010165 mit Blindwert).

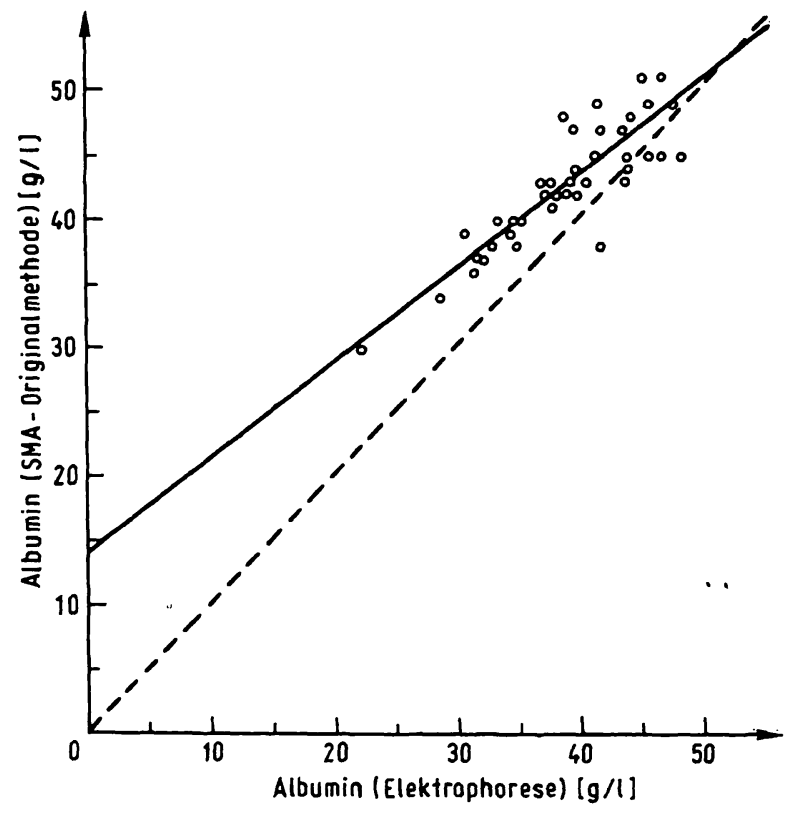

Abb. 2. Vergleich der gemessenen Albuminwerte am SMA 12/60 nach der Originalmethode und der Elektrophorese. Berechnung der Regression: $y\left(\right.$ SMA $\left._{\text {orig. }}\right)=14,06+0,732 \times($ Elpho $) ; r=0,887$.

\section{Ergebnisse und Diskussion}

Die lineare Regression der Albuminwerte, einmal bestimmt nach der Original-Bromkresolgrün-Methode auf dem SMA 12/60, zum anderen ermittelt nach elektrophoretischer Auftrennung der Serumproteinfraktionen, ist in Abbildung 2 dargestellt.

Der Albumingehalt am SMA 12/60 wird gewöhnlich mit Seren kalibriert, die Albumin in einer Konzentration von etwa $40 \mathrm{~g} / \mathrm{l}$ enthalten. Da üblicherweise Kontrollseren mit Albuminwerten in vergleichbaren Konzentrationsbereichen benutzt werden, wird im allgemeinen keine hohe Abweichung festgestellt. Eine zunehmende

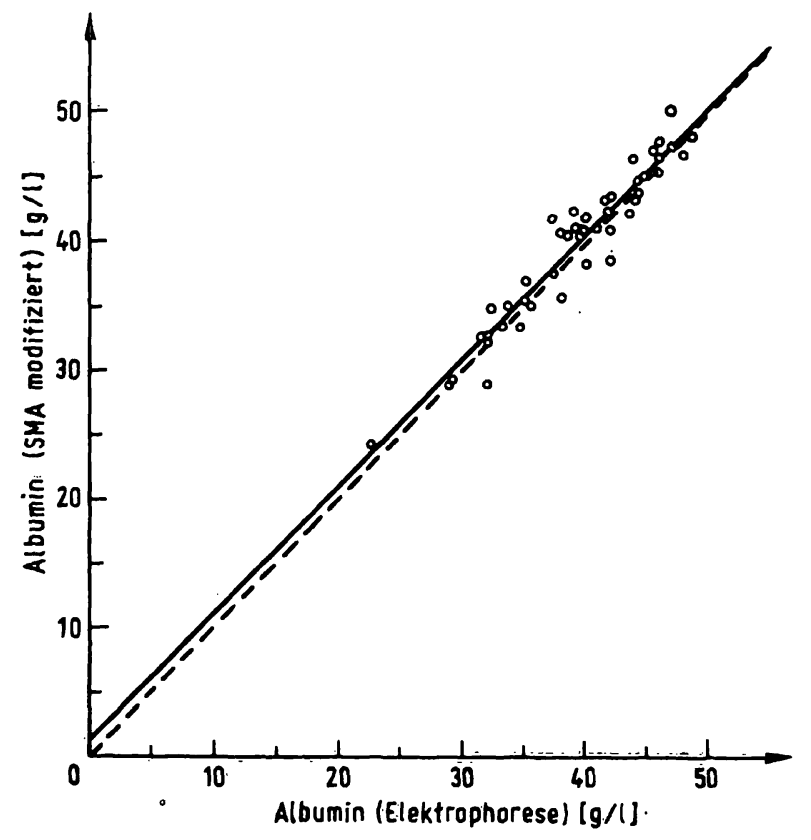

Abb. 3. Vergleich der gemessenen Albuminwerte bestimmt am SMA 12/60 nach der modifizierten Methode und der Elektrophorese.

Berechnung der Regressionsgeraden:

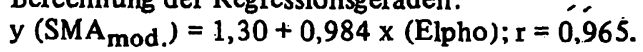


Diskrepanz zwischen beiden Methoden ist mit fallenden Albuminwerten, also gerade im klinisch interessanten Bereich, zu verzeichnen. In der Literatur finden sich hierzu widersprüchliche Angaben. Von einigen Autoren $(6,7)$ wird diese Diskrepanz nicht beschrieben, während andere Autoren $(8,9)$ darauf hinweisen. Die erheblichen Abweichungen veranlaßten Gustafsson, die Zeitabhängigkeit der Farbstoffentwicklung näher zu untersuchen. Hierbei beobachtete er eine schnelle Phase (1 Minute), in der im wesentlichen das Albumin reagiert und eine langsame Reaktion, in welcher auch andere Serumproteine, insbesondere Globuline aus der $\alpha_{2}$-Fraktion, mit Bromkresolgrün reagieren.

Um das Serumalbumin in der Routine möglichst selektiv zu erfassen, haben wir am SMA 12/60 die Reaktionszeit auf etwa 1/20 der ursprünglichen Zeit verkürzt (Abb. 1).

\section{Literatur}

1. Rodkey, F. L. (1965), Clin. Chem. 11, 478-487.

2. Doumas, B. T., Watson, W. A. \& Biggs, H. G. (1971), Clin. Chim. Acta 31, 87-96.

3. Technicon Method No SF 4-0030 FA7, Technicon Instr. Corp., Tarrytown, N. Y., USA, 1-5 (1977).

4. Webster, D., Bignell, A. H. C. \& Attwood, E. C. (1974), Clin. Chim. Acta 53, 101-108.

5. Schirardin, Von H. \& Ney, J. (1972), Z. Klin. Chem. Klin. Biochem. 10, 338-344.
Der Einfluß der Reaktionszeitverkürzung auf die Korrelation beider Methoden ist in Abbildung 3 dargestellt.

Die Albuminwerte von 45 Seren zeigen nach der modifizierten Methode gerade im Bereich der Hypalbuminämie eine bessere Úbereinstimmung mit den Elektrophoresebefunden als die nach der Originalmethode ermittelten Werte (Abb. 2 u. 3).

Die Linearität der modifizierten Methode wurde in einer Prüfperiode über 7 Wochen mit Albuminkonzentrationen von $13 \mathrm{~g} / 1$ bis $55 \mathrm{~g} / 1$ überprüft.

6. Corcoran, R. M. \& Durnan, S. M. (1977), Clin. Chem. 23, 765-766

7. Westgard, J. O. \& Pequette, M. A. (1972), Clin. Chem. 18, 647-653.

8. Cederblad, G., Hickey, B. E., Hollender, A. \& Ackerlund, G. (1978), Clin. Chem. 24, 1191-1193.

9. Gustafsson, J. E. C. (1976), Clin. Chem. 22, 616-622.

Dr. med. F. Keller Medizinische Universitätsklinik Josef-Schneider-Straße 2 Bau 4

D-8700 Würzburg 
. 